\title{
A higher prevalence of health problems in low income groups: does it reflect relative deprivation?
}

\author{
Karien Stronks, H Dike van de Mheen, Johan P Mackenbach
}

\begin{abstract}
Study objective-Although it has frequently been suggested that income affects health, there is hardly any research in which this issue has been explored directly. The aim of this study was, firstly, to examine whether income is independently associated with health, secondly, to assess the extent to which this association reflects high levels of deprivation in low income groups, and thirdly, to examine which specific components of deprivation contribute most to the link between income and health. Health indicators used were the prevalence of chronic conditions, health complaints and less than "good" perceived general health.
\end{abstract}

Setting-Region in the south east of the Netherlands.

Participants-A population of 2567 men and women who participated in an oral interview, aged 15-74.

Design-Data were obtained from the baseline of a prospective cohort study aimed at the explanation of socioeconomic inequalities in health.

Results-Large inequalities in health by (equivalent) income after differences in other socioeconomic indicators had been controlled for were observed. For example, among those in the lowest income group the risk of bad perceived health was three times as high as among people in the highest income group. The prevalence of deprivation (basic, housing, social) increased with decreasing income to approximately $50-60 \%$ in the lowest income group. A substantial part of the increased health risks of the lowest income groups could statistically be accounted for by the higher prevalence of deprivation in these groups. The components that are likely to influence health indirectly, through a psychological or behavioural mechanism, accounted for most of the effect.

Conclusions-These analyses provide evidence to suggest that a low income has detrimental health effects through relative deprivation. Moreover, the results indicate an indirect link between deprivation and health problems involving psychological or behavioural factors.

(F Epidemiol Community Health 1998;52:548-557)

Empirical studies in many countries show that people who are worst off as far as their socioeconomic position is concerned, are also worst off when it comes to health. ${ }^{1}$ According to current scientific opinion most of those socioeconomic inequalities in health arise as a consequence of the effect of social class on health, through specific risk factors. ${ }^{2}$ Risk factors that might be involved include behavioural factors, material/structural factors, and

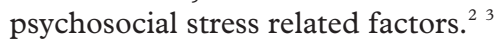

Some authors have argued that the inverse association between social class and health mainly reflects a causal effect of material factors. ${ }^{4-8}$ According to this view, the fact that people in lower socioeconomic groups are less healthy than their counterparts in higher positions is because of a differential access to material resources. Some evidence in support of this hypothesis is provided by data that show that the association between income and health is stronger than that between health and other indicators of socioeconomic status, such as educational or occupational class. ${ }^{59}$ It should be borne in mind however, that the association between income and health does not necessarily reflect a causal effect of income. Alternatively, this association might be because of the effect of other risk factors that are associated with, but not the consequence of, income, such as cultural differences. ${ }^{4} 6$ Secondly, the fact that the association between income and health is found to be stronger than that between education/occupation and health, is probably because of the reciprocal effect of health on income, through employment status. Such an effect is far less likely in the case of education and occupation. ${ }^{10}$ In addition, data on the association between income and health do not indicate the mechanisms that contribute to this link.

In this paper we will explore the link between income and health using more direct evidence. We will first specify the causal pathways by which income might affect health.

When thinking about the explanations for the income-health connection, absolute poverty is probably the first to arise. It indicates a situation in which someone has too little money to afford the basic necessities of life, including food, access to medical care, and clean drinking water. ${ }^{11}$

Although this concept might have some relevance for small groups in Western societies such as the homeless, it is self evident that absolute poverty of the sort that is common in some of the Third World countries is not found in Western European countries. According to the definition of absolute poverty that applies to the Third World countries, where people die as a direct consequence of a lack of food, clean drinking water or sewerage, hardly any poverty exists in industrialised countries. Therefore poverty in this study 
should not be conceptualised in absolute terms. Instead a definition should be chosen that is relevant to Western countries, implying a conceptualisation in terms of relative deprivation. ${ }^{12}$ One of the "relative approaches" to the concept of poverty defines disadvantage relative to living standards that are common in a specific society. ${ }^{13}$ According to the frequently cited definition of Townsend, people can be said to be deprived if "they lack the types of diet, clothing, household facilities and fuel and environmental, educational, working and social conditions, activities and facilities which are customary, or at least widely encouraged and approved, in the society to which they belong". ${ }^{14}$ Deprivation, according to this approach, is related to the access to material necessities, such as adequate food and heating, as well as social abilities, such as having social contacts with friends. Someone is said to be deprived if the access to these resources is limited relative to what is common in a certain society.

Although deprivation goes hand in hand with low income, there is no perfect association. People in lower income groups are not necessarily deprived (students may serve as an example), whereas a lack of resources indicates deprivation only when it is enforced by income. ${ }^{15}$ Income in itself is therefore not an adequate proxy of deprivation.

What is the nature of the relation between relative deprivation and health? The impact of absolute poverty on health is straightforward and even implicit within its definition: someone is said to be poor in an absolute sense if their material resources do not allow for the minimum standard for physical survival.

The causal mechanisms linking relative deprivation and health are less well understood. ${ }^{416}$ To some extent a direct effect might have some relevance in this context too. ${ }^{11}{ }^{17}$ Factors that are probably involved in this mechanism include adverse housing conditions, inadequate food or a lack of leisure activities. These resources do not indicate an absolute minimum that is necessary for survival as in the case of absolute poverty, but rather increase the risk of diseases or other health problems. The effect of damp and mould on the incidence of COPD is an example of this.

Secondly, relative deprivation might translate into ill health indirectly, involving among others behavioural factors. Part of socioeconomic inequalities in health have been shown to be because of behavioural factors such as smoking and physical exercise. ${ }^{18}$ As the social pattern of behaviour has been shown to be partly embedded in material living conditions such as deprivation, ${ }^{19}$ the latter are likely to affect health through behaviour. Living with a lack of material or social resources might, for example, act as a stressor and might induce people to engage in unhealthy behaviour such as smoking as a way of coping with deprivation. ${ }^{20}$ In addition, it might affect feelings of self esteem and the mental or emotional well being, which is likely to have a negative effect on health. ${ }^{11} 172122$
In summary, a low income might lead to deprivation, defined as a limited access to amenities and activities that are customary in a specific society. Being deprived is supposed to affect health directly, or indirectly, through a psychological or behavioural mechanism. The aim of this study is to explore this link between income and health. More specifically, the aim is: (1)To examine whether income is associated with health, independently of other socioeconomic and sociodemographic factors. (2)To assess to what extent the association between income and health reflects relative deprivation. (3) To examine which components of deprivation in particular contribute to the link between income and health. This might elicit indications of the mechanism by which deprivation affects health.

\section{Methods}

POPULATION

Data were obtained from the baseline data collection of the Dutch Longitudinal Study on Socio-Economic Health Differences (LSSEHD). This is a prospective cohort study that aims to explain socioeconomic inequalities in health in the Netherlands. The design and objective of this study have been described elsewhere in detail. ${ }^{3}$ It is based on a cohort of 15-74 year old, non-institutionalised people with Dutch nationality, in a region in the south east of the Netherlands - that is, the city of Eindhoven and a number of surrounding municipalities. An aselect sample of approximately 27000 people was drawn from the population registers, stratified by age (45-74 year old people were overrepresented) and postcode (to overrepresent the highest and lowest socioeconomic group). In April 1991, people in this sample were sent a postal questionnaire. The response rate was 70.1 per cent, resulting in a study population of 18973 persons, with relatively small differences across socioeconomic groups $(67 \%$ in the lowest to $73 \%$ in the highest) and other subgroups (for example, sex, age). A (random) subsample of approximately 3500 persons was drawn from those who responded to the postal questionnaire. This subsample was approached for a more extensive oral interview (May 1991). The response rate was $79.4 \%$, resulting in a study population of 2802 respondents. Differences in response between subgroups were again small, implying that this study population closely resembles the original sample as far as the distribution of sociodemographic characteristics is concerned. The analyses presented in this paper were based on the population that participated in the oral interview, as income was measured only among this subsample. Income information was not elicited from respondents who still lived with their parents, and they were therefore excluded from the analyses $(n=235)$. This resulted in a study population of 2567 respondents.

MEASUREMENTS

All variables were classified into categories to allow for linear and non-linear associations with health status. 
Table 1 Association between equivalent income and the prevalence of health problems (less than "good" perceived health, one or more chronic conditions, more than three health complaints). Logistic regression models ${ }^{\star}$ men and women, 15-74 years old $(n=2567)$

\begin{tabular}{|c|c|c|c|c|c|c|c|}
\hline \multirow{2}{*}{$\begin{array}{l}\text { Net equivalent income } \\
\text { per month, in Dutch } \\
\text { guilders }\end{array}$} & \multirow[b]{2}{*}{ Respondents (n) } & \multicolumn{2}{|c|}{$\geqslant 1$ chronic conditions } & \multicolumn{2}{|c|}{$\begin{array}{l}\text { Less than "good" perceived } \\
\text { general health }\end{array}$} & \multicolumn{2}{|c|}{$>3$ health complaints } \\
\hline & & OR & $C I$ & OR & $C I$ & $O R$ & $C I$ \\
\hline Less than 1100 & 253 & 1.46 & $0.98,2.17$ & 3.13 & $1.95,5.01$ & 2.90 & $1.90,4.43$ \\
\hline $1100-1399$ & 305 & 1.25 & $0.87,1.80$ & 2.34 & $1.50,3.66$ & 2.23 & $1.50,3.32$ \\
\hline $1400-1699$ & 407 & 1.21 & $0.87,1.69$ & 2.04 & $1.34,3.10$ & 2.10 & $1.45,3.04$ \\
\hline $1700-2099$ & 458 & 1.07 & $0.79,1.47$ & 2.27 & $1.53,3.39$ & 1.79 & $1.26,2.54$ \\
\hline 2100-2999 & 502 & 1.07 & $0.80,1.43$ & 1.33 & $0.90,1.98$ & 1.42 & $1.01,1.99$ \\
\hline $3000-6000$ & 353 & 1.00 & & 1.00 & & 1.00 & \\
\hline Missing & 289 & 0.94 & $0.66,1.35$ & 1.85 & $1.18,2.88$ & 1.88 & $1.27,2.78$ \\
\hline
\end{tabular}

*Also controlling for educational and occupational level, age, sex, marital status, religious affiliation, degree of urbanisation. OR = Odds ratio, $\mathrm{CI}=95 \%$ confidence intervals.

The income of the respondents is indicated by the household net income per month. As people sharing a household profit from economies of scale, the incomes of people living in families of different size and composition cannot be compared directly. To adjust for the number of persons inside and outside the household who had to live from the household income, and therefore for economies of scale, we divided the household income by an equivalence factor. We used a formula that is frequently applied in income inequalities studies, which consists of dividing the household income by the square root of the number of household members. ${ }^{23}$ When counting the number of household members, children were given less weight than adults. Following the recommendations of the Netherlands Central Bureau of Statistics, children were counted as 0.7 adult. ${ }^{24}$ The equivalent income (net household income divided by equivalence factor) therefore indicates the net income per month that is available for one person. The equivalent income was divided into six categories, which were chosen in such a way that each category contained at least 250 respondents, with the most detailed division at the lower end of the income distribution. This resulted in the following categories: less than 1100 Dutch guilders a month, 1100-1399, 1400-1699, 1700-2099, 2100-2999, and 3000-6000 Dutch guilders a month. We included the missings on income (11\% of the total population) as a separate category, to explore whether the results might be biased by the item non-response on this variable.
Three health indicators were used in these analyses. Firstly, chronic conditions were measured by means of a checklist, containing 23 chronic conditions, some of which were severe (such as cancer and heart disease), while others were less severe (such as serious headache and varicose veins). Respondents were classified according to whether (at the time of the survey) they reported that they were suffering from at least one of the conditions listed in the questionnaire. Some 48.2 per cent of the study population reported one or more chronic conditions. Secondly, health complaints were measured by means of a checklist, containing 13 questions on minor complaints about the heart, stomach, etc. Respondents were asked whether they suffered from any of these complaints. This variable was dichotomised into suffering from three or less compared with more than three complaints. Thirty five per cent of the population reported more than three complaints. Finally, perceived general health was indicated by the answer to the question "How do you rate your health in general?" The answer was dichotomised in the analysis into "(very) good" compared with less than "good" (fair, sometimes good and sometimes bad, bad). Some 29.5 per cent of the population perceived their health as less than "good".

Following the approach of Townsend, deprivation was defined in terms of a particular style/standard of living. Someone was said to be deprived if they could not participate in the living standard that is common to Dutch society. To identify people who can be said to be

Table 2 Association between deprivation and the prevalence of health problems (less than "good" perceived health, one or more chronic conditions, more than three health complaints). Logistic regression models ${ }^{\star}$, men and women, 15-74 years old

\begin{tabular}{|c|c|c|c|c|c|c|c|}
\hline \multirow[b]{2}{*}{ Deprivation } & \multirow[b]{2}{*}{ Respondents (n) } & \multicolumn{2}{|c|}{$\geqslant 1$ chronic conditions } & \multicolumn{2}{|c|}{$\begin{array}{l}\text { Less than "good" perceived } \\
\text { general health }\end{array}$} & \multicolumn{2}{|c|}{$>3$ health complaints } \\
\hline & & $O R$ & $C I$ & $O R$ & $C I$ & $O R$ & $C I$ \\
\hline \multicolumn{8}{|c|}{ Basic items lacking } \\
\hline 0 & 2093 & 1.00 & & 1.00 & & 1.00 & \\
\hline 1 & 334 & 1.13 & $0.87,1.47$ & 1.31 & $0.98,1.76$ & 1.31 & $1.00,1.71$ \\
\hline 2 & 90 & 1.78 & $1.08,2.93$ & 2.54 & $1.52,4.27$ & 1.92 & $1.18,3.12$ \\
\hline$\geqslant 3$ & 41 & 1.76 & $0.84,3.68$ & 2.15 & $0.98,4.74$ & 2.53 & $1.21,5.31$ \\
\hline \multicolumn{8}{|c|}{ Housing items lacking } \\
\hline 0 & 2404 & 1.00 & & 1.00 & & 1.00 & \\
\hline$\geqslant 1$ & 146 & 1.25 & $0.86,1.80$ & 1.24 & $0.81,1.89$ & 1.35 & $0.93,1.97$ \\
\hline \multicolumn{8}{|c|}{ Social items lacking } \\
\hline 0 & 2212 & 1.00 & & 1.00 & & 1.00 & \\
\hline 1 & 192 & 1.17 & $0.83,1.64$ & 1.51 & $1.05,2.18$ & 1.22 & $0.86,1.71$ \\
\hline 2 & 72 & 1.01 & $0.60,1.71$ & 1.60 & $0.93,2.75$ & 1.10 & $0.64,1.86$ \\
\hline$\geqslant 3$ & 80 & 1.88 & $1.07,3.28$ & 3.20 & $1.78,5.78$ & 2.59 & $1.48,4.56$ \\
\hline
\end{tabular}

*Also controlling for income, educational and occupational level, age, sex, marital status, religious affiliation, degree of urbanisation. $\mathrm{OR}=$ Odds ratio, $\mathrm{CI}=95 \%$ confidence intervals. 
Table 3 Percentage of deprived persons on basic, housing, and social dimension by equivalent income, men and women, $15-74$ years old. Standardised for sex and age $(n=2567)$

\begin{tabular}{|c|c|c|c|c|c|c|c|c|c|c|}
\hline \multirow{3}{*}{$\begin{array}{l}\text { Net equivalent income } \\
\text { per month, in Dutch } \\
\text { guilders }\end{array}$} & \multicolumn{10}{|c|}{$\%$ Of persons experiencing deprivation; number of items lacking } \\
\hline & \multicolumn{4}{|l|}{ Basic } & \multicolumn{2}{|c|}{ Housing } & \multicolumn{4}{|c|}{ Social } \\
\hline & 0 & 1 & 2 & $\geqslant 3$ & 0 & $\geqslant 1$ & 0 & 1 & 2 & $\geqslant 3$ \\
\hline Less than 1100 & 41.5 & 35.2 & 13.1 & 10.3 & 83.9 & 16.1 & 53.0 & 16.6 & 8.9 & 21.5 \\
\hline $1100-1399$ & 67.1 & 20.7 & 8.7 & 3.5 & 90.4 & 9.6 & 72.4 & 15.4 & 6.2 & 6.0 \\
\hline $1400-1699$ & 83.7 & 13.7 & 2.4 & 0.2 & 94.0 & 6.0 & 85.5 & 10.5 & 2.8 & 1.3 \\
\hline $1700-2099$ & 91.1 & 7.7 & 1.1 & 0.2 & 95.7 & 4.3 & 93.2 & 4.7 & 1.4 & 0.6 \\
\hline $2100-2999$ & 92.8 & 5.8 & 1.4 & - & 97.3 & 2.7 & 96.6 & 2.5 & 0.9 & - \\
\hline $3000-6000$ & 95.5 & 4.5 & - & - & 99.0 & 1.0 & 99.8 & 0.3 & - & - \\
\hline Missing & 78.2 & 16.3 & 2.5 & 3.0 & 92.4 & 7.5 & 88.2 & 7.1 & 2.1 & 2.0 \\
\hline Total population & 81.8 & 13.1 & 3.5 & 1.6 & 94.3 & 5.7 & 86.6 & 7.5 & 2.7 & 3.1 \\
\hline
\end{tabular}

deprived we used the checklist approach as developed by Townsend. ${ }^{13}$ On the basis of several Dutch questionnaires, we composed a list of activities, amenities, and resources that are commonly regarded as essential, in other words, necessities. The respondents were asked to indicate whether they had a particular item. If the answer was "no", they were asked explicitly whether this was because they could not afford it or for another reason. The aim was to distinguish between people who choose not to have that particular item and people who do not have that item because of financial constraints. Respondents were classified as deprived if they could not afford one or more of these necessities because of financial reasons. ${ }^{12}$ If they did not have a particular item for other than financial reasons, this was supposed to indicate a choice. Following the results of a study by Callan et $a l^{15}$ we made a distinction between a basic and social dimension.

The basic items relate to items that most people in Western societies perceive as necessities. ${ }^{15} 25$ These include: having at least one hot meal a day, eating meat/fish four or more times a week (the prevalence of vegetarianism is rather low-that is, about $6 \%$ in the study population), no debts for daily living, paying house rent, etc, without problems, having sufficient heating, buying new clothes regularly, being able to save if necessary. People were classified as deprived if they were not able to afford (because of financial reasons) one or more amenities or expenditures from this list of seven. Four categories were distinguished- that is, can afford all items, can afford all items but one, can afford all items but two, cannot afford three or more items.

People were defined as socially deprived if they were not able to engage in one or more of seven activities listed in the questionnaire. These include: going out regularly, taking a holiday once a year, having friends for dinner regularly, membership of a club, leisure activities, access to car, telephone. Four categories were distinguished-that is, can afford all items, can afford all items but one, can afford all items but two, cannot afford three or more items.

In addition the questionnaire contained some issues related to housing conditions and amenities, including owning a refrigerator or owning a washing machine, living in a dry and damp free dwelling, and overcrowding. People were defined as deprived if they were not able to afford one of these amenities or if they reported complaints with respect to mould/ cold, or if they had less than one room per person (crowding).

Occupational level of the main breadwinner and educational level of the respondent were considered to be confounding variables, as they are associated with, but not the consequence of, a certain income level. The educational level of the respondent was divided into seven categories: primary school only; lower general education; lower vocational education; intermediate vocational education; intermediate/ higher general education; higher vocational college; and university. The occupational level

Table 4 Contribution of individual deprivation items to the association between equivalent income and the prevalence of less than "good" perceived health. Logistic regression models ${ }^{\star}$, men and women, $15-74$ years old $(n=2137) \dagger$

\begin{tabular}{|c|c|c|c|c|c|c|c|c|c|}
\hline \multirow{2}{*}{$\begin{array}{l}\text { Net equivalent income } \\
\text { per month, in Dutch } \\
\text { guilders }\end{array}$} & & & \multicolumn{7}{|c|}{ OR after controlling for individual deprivation items: basic dimension $\neq$} \\
\hline & \multicolumn{2}{|c|}{$\begin{array}{l}\text { OR and CI controlling for } \\
\text { confounders }\end{array}$} & Meat/ fish & Heating & Clothes & Debts & $\begin{array}{l}\text { Financial } \\
\text { problems }\end{array}$ & Savings & \\
\hline \multirow{6}{*}{$\begin{array}{l}\text { Less than } 1100 \\
1100-1399 \\
1400-1699 \\
3000-6000\end{array}$} & 2.58 & $1.55,4.27$ & 2.52 & 2.59 & 2.21 & 2.47 & 2.53 & 2.30 & \\
\hline & 1.93 & $1.20,3.09$ & 1.92 & 1.93 & 1.75 & 1.90 & 1.93 & 1.83 & \\
\hline & 1.87 & $1.21,2.89$ & 1.87 & 1.87 & 1.81 & 1.86 & 1.87 & 1.82 & \\
\hline & 1.00 & & 1.00 & 1.00 & 1.00 & 1.00 & 1.00 & 1.00 & \\
\hline & & & \multicolumn{7}{|c|}{ OR after controlling for individual deprivation items: social dimension } \\
\hline & & & Car & Telephone & $\begin{array}{l}\text { Leisure } \\
\text { activities }\end{array}$ & Going out & Holiday & $\begin{array}{l}\text { Friends for } \\
\text { dinner }\end{array}$ & Membership club \\
\hline \multirow{4}{*}{\multicolumn{3}{|c|}{$\begin{array}{l}\text { Less than } 1100 \\
1100-1399 \\
1400-1699 \\
3000-6000\end{array}$}} & 2.45 & 2.58 & 2.42 & 1.93 & 2.35 & 2.33 & 2.43 \\
\hline & & & 1.89 & 1.98 & 1.86 & 1.68 & 1.85 & 1.87 & 1.92 \\
\hline & & & 1.84 & 1.87 & 1.86 & 1.71 & 1.82 & 1.87 & 1.86 \\
\hline & & & 1.00 & 1.00 & 1.00 & 1.00 & 1.00 & 1.00 & 1.00 \\
\hline
\end{tabular}

*Also controlling for educational and occupational level, age, sex, marital status, religious affiliation, degree of urbanisation. †The number is different from the number of respondents in the figures, because of a different number of missing values. $¥$ The odds ratios when controlling for "having at least one hot meal a day" could not be estimated because of the small number of people who lacked this item. OR=Odds ratio, CI=95\% confidence intervals. 


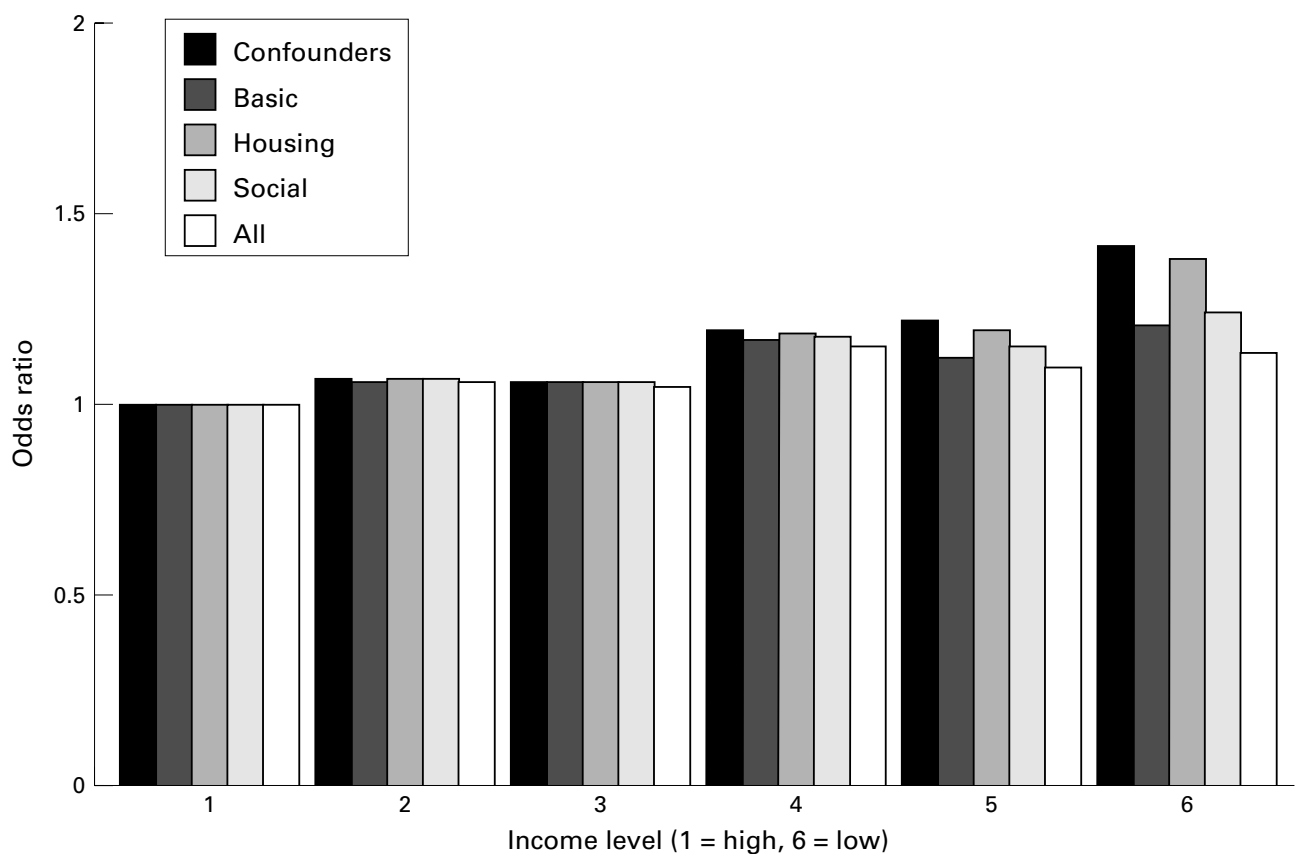

Figure 1 Chronic conditions by equivalent income: explanation by deprivation. Results of logistic regression models ${ }^{*}$, $15-74$ year olds, men and women. ${ }^{\star}$ Also including educational and occupational level, age, sex, marital status, religious affilation, degrees of urbanisation.

of the main breadwinner was determined on the basis of the current occupation if in paid employment, or if not, the last paid employment. The occupations were classified according to five levels outlined in the Erikson, Goldthorpe and Portocarero (EGP) schemethat is, higher grade professionals; lower grade professionals and routine non-manual employees; self employed; high and low skilled manual workers; unskilled manual workers. ${ }^{26}$ People who had never been in paid employment formed the sixth category. If the respondent did not live with a partner, they were automati- cally classified as the main breadwinner. If the respondent lived with a partner, they were asked who the main breadwinner was.

The other confounding variables that have been taken into account are (number of categories between brackets): sex, age ( 5 years age groups), marital status (4), religious affiliation (4) and degree of urbanisation (5).

\section{ANALYSES}

To determine whether income and deprivation were associated with health, logistic regression models were fitted, controlling for potential

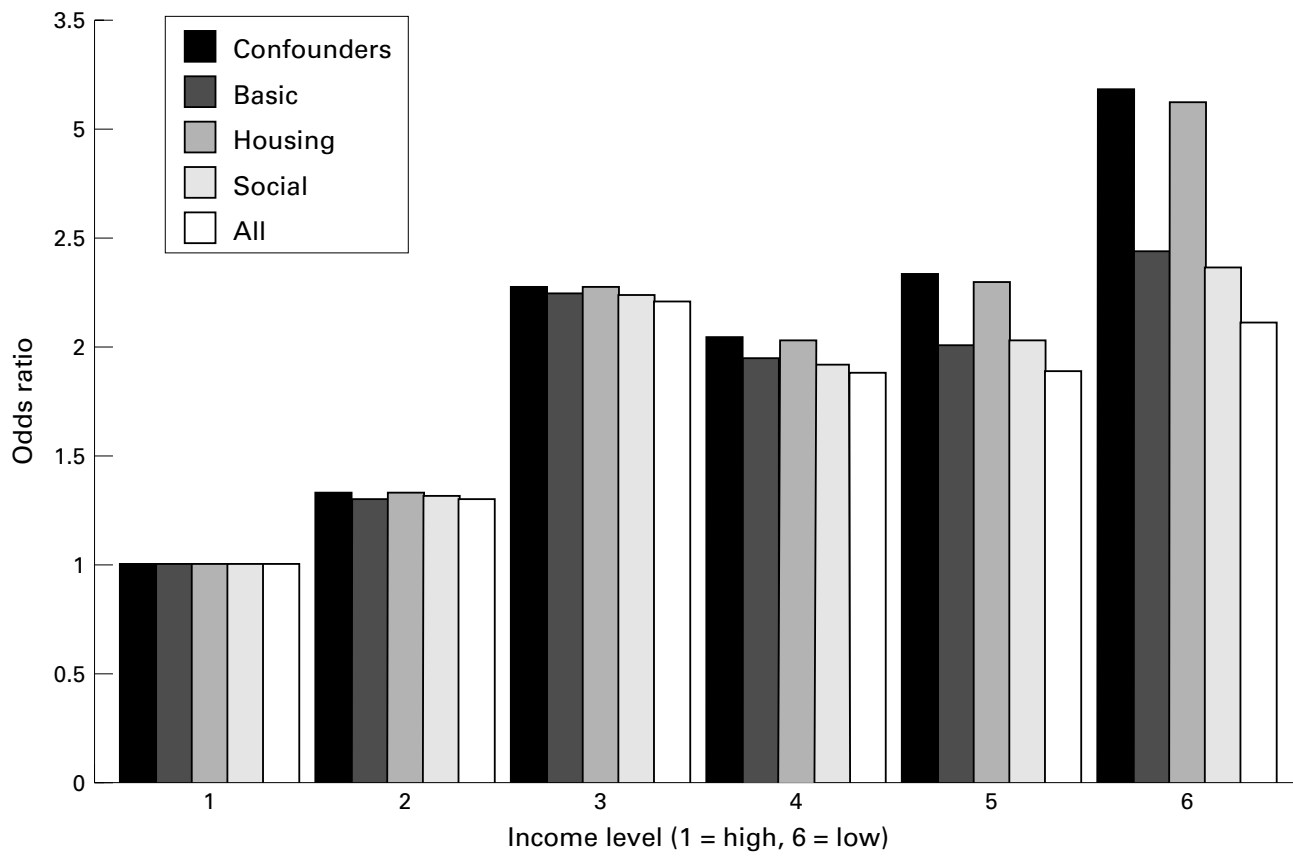

Figure 2 Perceived general health by equivalent income: explanation by deprivation. Results of logistic regression models ${ }^{*}$, 15-74 year olds, men and women. ${ }^{\star}$ Also including educational and occupational level, age, sex, marital status, religious affilation, degree of urbanisation. 


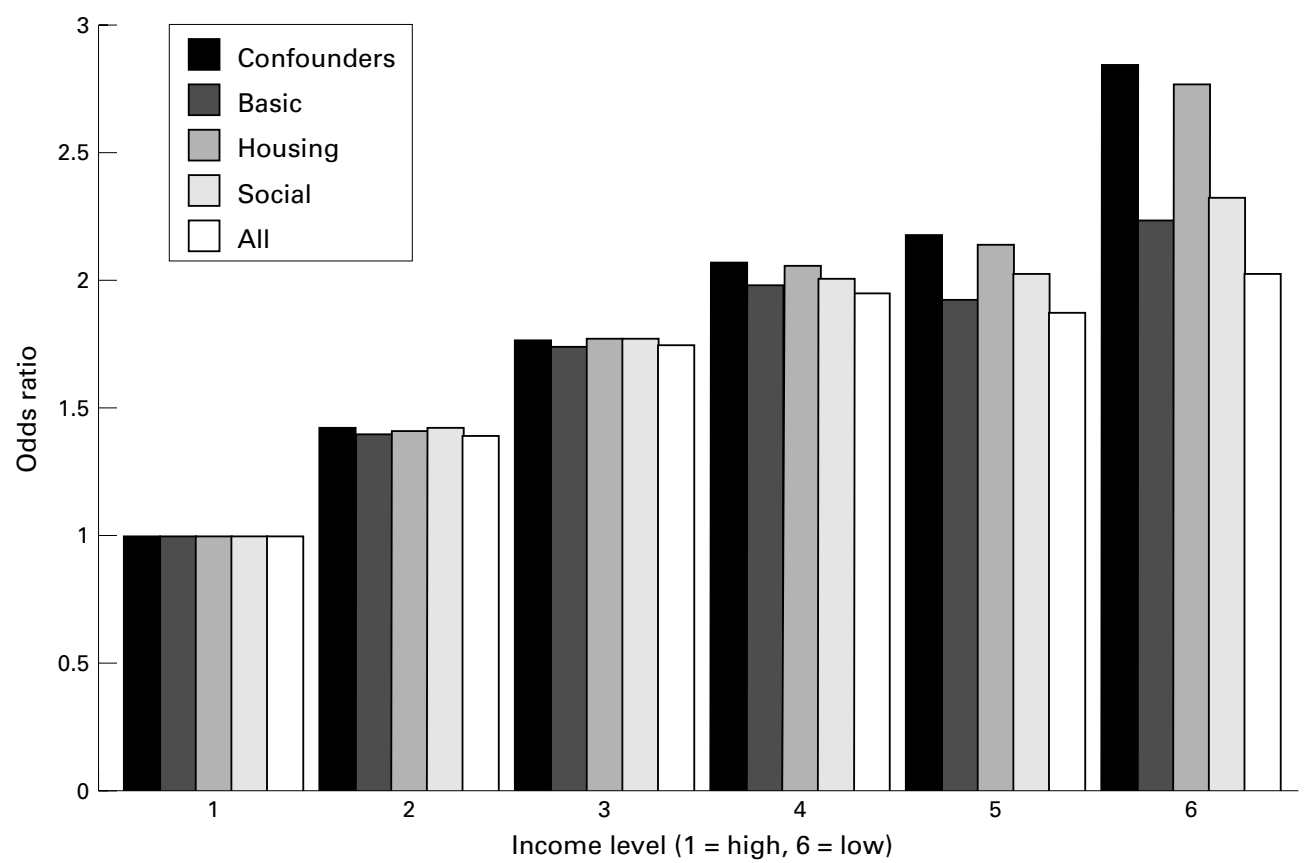

Figure 3 Health complaints by equivalent income: explanation by deprivation. Results of logistic regression models ${ }^{*}$, 15-74 year olds, men and women. ${ }^{\star}$ Also including educational and occupational level, age, sex, marital status, religious affilation, degree of urbanisation.

confounders (including other socioeconomic indicators). The regression coefficients and their standard errors were used to calculate odds ratios and their $95 \%$ confidence intervals. The reduction in deviance because of the inclusion of income was used as an overall statistical test of its effect. The highest income group and those who were classified as non-deprived were used as a reference category.

To describe the distribution of deprivation among income groups, we calculated the percentages in each category, directly standardised for age (10 years age groups) and sex.

To estimate the extent to which income differences in health reflect differences in deprivation, we included the deprivation variables in the logistic regression model already containing income and the confounding variables. The reduction in the odds ratios of income because of the adjustment of the deprivation variables was used to indicate the latter's contribution to the income gradient in health. To explore the contribution of specific components of relative deprivation, each item was added to a model containing income and the confounding variables. The reduction in odds ratios of income because of the adjustment for these variables was used to indicate the importance of each item. The analyses were carried out with the logistic regression module of Egret. ${ }^{27}$

\section{Results}

We firstly examined the bivariate associations between income, deprivation and health.

Table 1 shows the association between equivalent income and health problems, as assessed by means of logistic regression. The relative risk of the highest income group is set at 1 . The odds ratios indicate how much more likely it is for a person with a certain income to have a health problem compared with those in the highest income group. Both health complaints and perceived general health were statistically significantly related to equivalent income after confounders (including educational and occupational level) were controlled for. The odds ratios steadily increased with decreasing income, and the odds of the lowest income group was approximately three times as high as that of the highest income group. The odds ratios for chronic conditions also increased in lower income groups, although not statistically significantly and to a lesser extent than for the subjective indicators. Among people for whom data on the level of income were missing, the risk of health problems was comparable to that in the middle income categories.

We observed a positive association between deprivation and health problems as far as the basic and social items are concerned (table 2). As compared with people who were not deprived, the odds ratios among the deprived were statistically significantly increased. In general, the more intense the deprivation - that is, the higher the number of items lacking, the higher the risk of health problems. Adverse housing conditions were not significantly related to health status. The risks of reporting chronic conditions in lower income groups were also significantly increased, but they were again smaller than for the subjective health measures.

Not surprisingly, deprivation and income were associated (table 3 ). The percentage of deprived people steadily increased with decreasing income. Moreover, intense deprivation was found to be more common among the lower income groups. Most of the deprived people in the higher and middle income categories experienced a single form of 
deprivation only. There was still a relatively high percentage of people in the lowest income categories who were not deprived, implying that a low income not necessarily indicates deprivation.

Figures 1-3 show the risk of health problems in each income group after differences in deprivation had been controlled for. The figures indicate that the high prevalence of health problems in low income groups partly reflects high levels of deprivation. After differences in all deprivation measures had been controlled for, the risk of the two lowest income groups decreased by a maximum of $50 \%$. Basic and social deprivation seemed to account for most of the effect. They were of similar importance. Deprivation with respect to housing conditions hardly accounted for the income gradient in health. An examination of the risk of health problems among the most deprived in the lowest income group (data not shown), showed that their risk of reporting less than "good" perceived health or health complaints was approximately seven times as high as among those in the highest income category.

After allowing for the inclusion of all deprivation measures in the model, some income inequalities in health remained. Firstly, the higher risk of health problems in the lower income groups could not totally be explained by deprivation. Secondly, the increased health risks of the higher and middle income groups was hardly accounted for by deprivation, because of the low prevalence of deprivation in these groups.

Finally, we studied which components of relative deprivation in particular accounted for the effect in the lowest income categories. The results for one health indicator-that is, perceived general health, are shown as an example (table 4). The results for the other health measures were comparable. Deprivation with respect to housing was omitted as this factor hardly accounted for the effect of income (figures 1-3).

The item relating to "going out regularly" seemed to account for most of the effect of social deprivation. Other social items that contribute substantially to the association between income and health relate to the ability of "having friends for dinner regularly" and "taking a holiday once a year". The specific basic items that appeared to account for the effect include the ability "to save (if necessary)" and "to buy new clothes regularly". Those items that are likely to affect health directly - that is, those related to food and heating, seemed to contribute only marginally to the association between income and health. This was because of their low prevalence as well as their weak relation with health.

\section{Discussion}

The aim of this paper was to examine the health effect of income. It was hypothesised that this effect partly reflects high levels of relative deprivation. We found income to be independently associated with health. Also deprivation, and especially intense deprivation, was found to be associated with health status. The

\section{KEY POINTS}

- There is hardly any direct evidence of the causal effect of low income on health.

- In this study, both income and deprivation were independently associated with (self reported) health.

- The high prevalence of health problems in low income groups partly reflects the health effects of relative deprivation.

- Rather than directly, relative deprivation seems to affect health indirectly through a psychological and behavioural mechanism.

- The health effects of deprivation in low income groups warrant a policy response.

relatively high prevalence of deprivation in the lowest income groups was found to account for approximately half of their increased risks of health problems. Because of its low prevalence, deprivation hardly affected the increased risk of health problems in the middle income groups. The data provide evidence in support of an indirect link between deprivation and health, involving psychological or behavioural factors.

The estimation of the association between income and health might have been biased by non-response. If, for example, ill people with an extremely low income had not participated in the study, we would have underestimated the association between income and ill health. We do not expect our results to be substantially biased by non-response however, as the sample studied here highly resembles the original sample as far as sociodemographic characteristics are concerned. ${ }^{3}$ Nor do we expect the item non-response on the income variable to substantially bias the results, as the health risk of people who did not report their income was only slightly increased.

The main limitation of this study relates to the use of cross sectional data. Whereas our aim was to examine a causal effect of income, the association between income and health as shown in table 1 might also reflect the reciprocal effect-that is, an effect of health on income. To examine the extent to which a selection mechanism is operative in this respect, we assessed the risks of health problems in low income groups after excluding the long term disabled from the population (results not shown). The underlying rationale of this analysis is the premise that the selection effect is most apparent among the long term disabled. As people in this group are not in paid employment because of health problems, leading to a lowering in income, their relatively low income partly reflects an effect of ill health. ${ }^{10}$ As expected, after the exclusion of this group, the risk of the lower income categories decreased. This finding confirmed our expectation, before the analyses, that the higher prevalence of health problems in these groups might partly reflect a selection effect. It should be acknowledged however, that also the association between deprivation and health might be caused by a reciprocal effect as 
deprivation is the consequence of a low income. We do not expect this effect to be sufficiently powerful, however, to affect the conclusion that income has a substantial impact on health, through deprivation. This expectation is based on the finding that excluding the long term disabled hardly lowered the contribution of deprivation to the increased risks of the low income groups (results not shown). This implies that, although the effect of income on health might be somewhat smaller than indicated in our data, the results nevertheless provide evidence to suggest that the income-health association reflects an effect of deprivation in low income groups.

Another reverse effect that might be operative relates to the impact of health problems on deprivation through health related costs. If ill people incur high expenditures as a result of their illness, less money will be available to meet other needs. As a result, the higher deprivation among the ill might also be the consequence of health problems. We do not expect this mechanism to seriously threaten our results however, as the results of another study based on the same dataset indicate that expenditures as a result of illness are rather high only for a small proportion of the chronically ill. ${ }^{28}$

Secondly, there is a possibility that the results are biased because of the fact that the measurement of deprivation was based on self report. The definition of poverty that is used in this paper fits the so called "lifestyle" approach, which defines poverty in terms of a particular style and standard of living. Following the frequently used approach of Townsend, this style/ standard was operationalised by means of a checklist of items that are generally considered as necessities. If people do not participate in this "average" lifestyle, this can reflect personal choice as well as available income. To distinguish between "constraints" and "choice" we defined people as deprived only if they could not afford one or more items because of financial reasons. It should be acknowledged however, that there might be some problems in this more subjective approach. Firstly, even if someone says they cannot afford a particular item, this might reflect a personal choice not to buy that particular item (for example, a car) in favour of another item (for example, a holiday). This does not seem to affect our conclusions, however, as in the analyses we counted the number of items lacking. This sum score, in our view, is less sensitive to this possible mixture of choice and constraint.

Furthermore the results could have been affected by the fact that both health and deprivation were based on self report, if the reporting of both variables had been affected by some third factor, such as the tendency to complain. This would probably have led to overestimating the contribution of deprivation. Although only the use of health measures that are objectively measured could give more insight into the importance of this potential bias, we do not expect this bias to seriously threaten our conclusions. The main argument to support this view is that the questions used to indicate deprivation elicit a very precise description of the deprived situation. For example people were asked to say whether they were able to go out at least once in two weeks, instead of, for example, "regularly". Such a precise description seems to leave little room for complaining. Furthermore, deprivation was also found to be associated with the more objective health indicator - that is, chronic conditions. The report of this health indicator is less likely to be affected by feelings and emotions than that of the other health indicators. Finally, as the percentage that reported lacking two items or more was rather low (about 5\%), it seems unlikely that the overall prevalence of deprivation has been overestimated in this study, although this does not completely rule out the possibility of an overestimation in specific socioeconomic groups.

However, another possible bias might have led to an underestimation of the association between deprivation and health. This relates to the imprecision and incompleteness of the measurement of deprivation. The deprivation items included in this study are clearly not perfect markers for real deprivation. In particular physical aspects such as dietary patterns and housing conditions could not adequately be captured in the questionnaire. Therefore it is likely that the importance of deprivation has been underestimated, in particular as far as the material components are concerned. Finally, also (non-differential) misclassification of deprivation might have led to an underestimation of the association between deprivation and health. This implies that the real association might even be stronger than indicated in this study.

The independent association between income and health as demonstrated in this study is consistent with the results of other studies. ${ }^{52930}$ This association does not necessarily indicate a causal effect of income on health. Apart from the disturbing effect of a selection mechanism, other explanatory factors that are causally related to income might be operative. Cultural variation might serve as example. As people in higher and lower income groups differ with respect to sociocultural factors that are causally unrelated to income, part of the relation between income and health might wrongly be attributed to a causal effect. Some studies have tried to overcome this bias by controlling for other risk factors, such as smoking. ${ }^{31}{ }^{32}$ However, as some of these factors might also be involved in the causal pathway connecting income and health, this probably yields an underestimation of the effect of income on health.

This paper has examined the causal health effect of income in a more direct way, thereby focusing on the role of deprivation. The results provide evidence to suggest that a low income has an independent effect on health. In a multivariate analysis the increased risk of health problems in the two lowest categories could for a large part be traced to the high prevalence of (intense) basic and social deprivation. As income provides the basic prerequisites for health, such as food, shelter, and the ability to 
participate in society, these results suggest that the level of income at the bottom of the social stratification is too low to allow for these prerequisites, and, more importantly, that this has a detrimental effect on health.

Implicit within the concept of deprivation is its clustering in lower income groups. Deprivation could therefore not account for the increased risk of health problems in the middle and higher income groups. This implies that other explanatory mechanisms are operative here. The health effect of income inequality rather than the health effects of a low income in itself, is such a potentially explanatory mechanism. Studies showing an association between income inequality and life expectancy at the macro-level provide evidence in support of this. ${ }^{21}$ Whereas the mechanism of relative deprivation explored here is expected to operate through a low income, the mechanism suggested by Wilkinson acts through the relative position of an individual in the income distribution, involving psychosocial factors. The relevance of this mechanism for the explanation of health inequalities among the higher and middle income groups should be tested in future research, thereby indicating this and probably also other mechanisms involved in a direct way.

We found little evidence to suggest the importance of a direct health effect of deprivation. Firstly, physical housing conditions were found to contribute only marginally to observed health inequalities, because of the fact that they were almost unrelated to health problems. Also other items that might affect health directly (food, heating) hardly accounted for the health effect of income. Not only because they were only weakly related to health, but also because of their low prevalence. However, as mentioned before, the failure to demonstrate a direct effect might also be because of those aspects of deprivation that directly influence health were not adequately covered in this study.

The analysis of the contribution of individual components indicated a large contribution for those items that are related to social participation, such as having friends for dinner or going out regularly. The relatively strong association between these items and health is in accordance with the results of a British study. ${ }^{33}$ These components are likely to influence health indirectly, through, for example, self esteem. A positive self esteem, indicating the beliefs that a person holds about themself has been shown to be important for individual well being. ${ }^{22}$ The results of these analyses therefore indicate the importance of a psychological link between deprivation and health. The fact that we found those basic items that are likely to affect health indirectly, such as "being able to save" or "to buy clothes regularly" contribute most to the association between income and health, supports this view.

Furthermore, the importance of the psychological mechanism is suggested by the finding that the income-health relation differed according to the health indicator used. If it is assumed that the health indicators "perceived general health" and "health complaints" more than chronic conditions cover mental aspects of health status, the stronger effect of income through deprivation on the former is in accordance with a prominent role for the psychological mechanism. In addition, this implies that our results might not be automatically generalised to other health indicators such as the higher death rates among the deprived. Future studies, using longitudinal data and objective indicators of health should further explore this issue.

Apart from a psychological link, the association between deprivation and health might also be mediated by behavioural factors. In particular qualitative studies provide evidence to suggest the importance of such a link. These studies indicate that people may engage in smoking as a way of coping behaviour when confronted with the stress of disadvantaged circumstances. ${ }^{20}$ A similar mechanism might be operative for alcohol consumption, although available studies show inconsistent results. ${ }^{34}$ In addition, behavioural factors such as physical exercise might be linked to deprivation in the sense that the possibilities to engage in this health promoting behaviour might be limited by financial means.

Behavioural factors were not included in the analyses that were reported in this paper. Another study, which was based on the same dataset, provides evidence to suggest the importance of the behavioural mechanism, however. In that study, relating to the determinants of the social pattern of smoking, the higher prevalence of smoking in lower socioeconomic groups could for a large part be traced to the higher prevalence of financial problems in these groups. ${ }^{35}$

In conclusion, although our study is limited in several respects, its results provide evidence in support of a causal effect of income on health. Whereas the relative high percentage of persons experiencing deprivation in lower income groups in itself warrants a policy response, the health effects of deprivation are an extra argument to intervene in this situation. As the Netherlands is characterised by a rather generous social services system, guaranteeing equal opportunities for education, equal access to health care services, an income in the case of illness, etc, the extent to which income determines the access to health related resources is probably rather modest. This suggests that in countries with a less developed welfare state the link between income and deprivation might even be stronger.

Funding: the LS-SEHD is supported financially by the Prevention Fund, and the Ministry of Public Health Welfare and Sport. It forms part of the GLOBE study ("Gezondheid en Levensomstandigheden Bevolking Eindhoven en omstreken"). The GLOBE study is being carried out by the Department of Public Health of Erasmus University Rotterdam, in collaboration with the Public Health Services of the city of Eindhoven, the region of Geldrop-Valkenswaard, and the region of Helmond. The GLOBE study as a whole is supported financially by the Prevention Fund ("Praeventiefonds"), the Ministry of Public Health, Welfare and Sport, the Sick Fund Council ("Ziekenfondsraad"), the Netherlands Organization for the Advancement of Research ("NWO"), Erasmus University Rotterdam, and the National Commission for the Chronically Ill ("NCCZ")

Conflicts of interests: none. 
1 Fox J, ed. Health inequalities in European countries. Aldershot: Gower Publishing, 1989.

2 Davey Smith G, Bartley M, Blane D. Explanations for socio-economic differentials in mortality. Evidence from Britain and elsewhere. Eur f Public Health 1994;4:131-44.

3 Mackenbach JP, Mheen $\mathrm{H}$ van de, Stronks K. A prospective cohort study investigating the explanation of socioeconomic inequalities in health in the Netherlands. Soc Sci Med 1994;38:299-308.

4 Townsend P, Davidson N, eds. The Black Report. In: Townsend P, Davidson N, Whitehead M, eds. Inequalities in health. London: Penguin Books, 1988:31-213.

5 Blaxter M. Health and lifestyles. London: Tavistock Routledge, 1990.

6 Quick A, Wilkinson R. Income and health. London: Socialist Health Association, 1991.

7 Davey Smith G, Bartley M, Blane D. The Black Report on socio-economic inequalities in health 10 years on. BMF

8 Davey Smith G, Egger M. Socioeconomic differentials in wealth and health. Widening inequalities in health - the wealth and health. Widening inequalities in health

9 Morris JN, Blane DB, White IR. Levels of mortality, education and social conditions in the 107 local education authority areas of England. $\mathcal{F}$ Epidemiol Community Health 1996;50:15-17.

10 Stronks K, Mheen $\mathrm{H}$ van de, Bos J van den, et al. The interrelationship between income, health and employmen status. Int $\mathcal{F}$ Epidemiol 1997;26:592-600.

11 Blackburn C. Poverty and health. Working with families. Buckingham: Open University Press, 1991.

12 Piachaud D. Problems in the definition and measurement of poverty. Fournal of Social Policy 1987;16:147-64.

13 Townsend P. The international analysis of poverty. New York: Harvester Wheatsheaf, 1993.

14 Townsend P. Deprivation. Fournal of Social Policy 1987;16: $125-46$.

15 Callan T, Nolan B, Whelan CT. Resources, deprivation and the measurement of poverty. Fournal of Social Policy 1993;22:141-72.

16 Vågerö D, Illsley R. Explaining health inequalities: beyond Black and Barker. Eur Sociol Rev 1995;11:1-23.

17 Benzeval M, Judge $K$, Whitehead $M$. Tackling inequalities in health. An agenda for action. London: King's Fund 1995.

18 Marmot MG, Rose G, Shipley M, et al. Employment grade and coronary heart disease in British civil servants. $\mathcal{F}$ Epidemiol Community Health 1978;32:244-9

19 Stronks $\mathrm{K}$, Mheen $\mathrm{H}$ van de, Looman CWN, et al. Behavioural and structural factors in the explanation of socio-economic inequalities in health: an empirical analysis. Sociol Health Illness 1996;18:653-74.
$20 \mathrm{Graham} \mathrm{H}$. When life's a drag. Women, smoking and disadvantage. London: HMSO, 1993.

21 Wilkinson RG. National mortality rates: The impact of inequality? Am f Public Health 1992;82:1082-4.

2 Stroebe W, Stroebe MS. Social psychology and health. Buckingham: OUP, 1995.

23 Atkinson $\mathrm{AB}$, Rainwater L, Smeeding $\mathrm{TM}$. Income distribution in OECD countries. Paris: OECD, 1995.

24 Schiepers JMP. Huishoudequivalentiefactoren volgens de budgetverdelingsmethode [in Dutch]. Sociaal-Economische Maandstatistiek 1988; [suppl 2].

25 Berghman J, Muffels R, Vries A de, et al. Armoede, bestaansonzekerheid en relatieve deprivatie [in Dutch]. Tilburg: Katholieke Universiteit Brabant, 1988.

26 Erikson R, Goldthorpe JH, Portocarero L. Intergenerational class mobility and the convergence thesis: England, France and Sweden. Br F Sociol 1983;34:303-43 .

27 Statistics and Epidemiology Research Corporation. Egret reference manual. Seattle: 1990.

28 Agt HME van, Stronks K, Mackenbach JP. De financiële situatie van chronisch zieken [in Dutch]. Rotterdam: Erasmus Universiteit Rotterdam, 1996.

29 Ooijendijk WTM, Schaapveld K. Sociaal-economische status, gezondheid en medische consumptie [in Dutch]. In: Mackenbach JP, ed. Sociaal-economische gezondheidsverschillen onderzocht, deel 4. Rijswijk: Ministerie van WVC, 1992.

30 Wilkinson RG. Class mortality differences, income distribution and trends in poverty 1921-1981. Fournal of Social Policy 1989;18:307-35.

31 Haan M, Kaplan GA, Camacho T. Poverty and health. Prospective evidence from the Alameda County Study. Am $\mathcal{F}$ Epidemiol 1987;125:989-98.

32 Hahn RA, Eaker E, Barker ND, et al. Poverty and death in the United States - 1973 and 1991. Epidemiology 1995;6:490-7.

33 Benzeval M, Judge K, Solomon M. The health status of the Londoners. A comparative perspective. London: King's Fund Institute, 1992.

34 Romelsjö A, Lazarus NB, Kaplan GA, et al. The relationship between stressful life situations and changes in alcohol consumption in a general population sample. British Fournal of Addiction 1991;86:157-69.

35 Stronks K, Mheen $\mathrm{H}$ van de, Looman CWN, et al. Cultural, material and psychosocial correlates of the socio-economic gradient in smoking behavior in adults. Prev Med 1997;26: 754-66. 